\title{
The Effectiveness of Posturicular Fascial Flap as an Adjunct to Suture Otoplasty
}

\author{
Ari Raheem Qader ${ }^{1}$, Dana Abdulmagid Abdilkarim²*, Salah Ahmed Mohammed ${ }^{3}$ \\ ${ }^{1}$ Department of Surgery, University of Sulaimani, Sulaimani, Kurdistan Region, Iraq. \\ ${ }^{2}$ Department of Community Health, Sulaimani Polytechnic University, Sulaimani, Kurdistan Region, Iraq. \\ ${ }^{3}$ Department of Health, Dohuk General Directorate of Health, Dohuk, Kurdistan Region, Iraq. \\ ${ }^{*}$ Corresponding Author: dana dr77@yahoo.com
}

Received | November 29, 2015

Accepted | January 13, 2016

\section{Abstract}

Mustardé technique of otoplasty is probably the most famous and practical among all otoplasty procedures especially in our centers. Yet it possesses the risk of suture extrusion, stitch granulomas and recurrence. Such complications have been reported, albeit few, yet they are bothersome to patients and their families. Placing tissues between the suture lines and the postauricular incision whether grafts or fascial flaps have been reported to reduce these complications.

This study was set to evaluate the effectiveness of elevating a post-auricular fascial flap to cover the sutures in Mustardé and Furnas techniques for reducing the risk of suture extrusion and granulomas and possibly recurrence. Eleven patients with prominent ears (21 ears) fit our inclusion criteria. Nine of them were males and two females. They underwent suture otoplasty with post-auricular fascial flap in Burn and Plastic Surgery Hospital in Sulaimania from December 2011 to July 2015. Their mean age was 15.5 years, with a mean follow-up period of $\mathbf{2 4 2}$ days (ranged from 66 days to $\mathbf{4 3 1}$ days. Polydioxanone suture was used in (6 ears), and polypropylene suture was used in (15 ears).

We achieved $91 \%$ satisfaction rates among patients and their families (only one patient was unsatisfied). One patient developed partial recurrence of the middle half of antihelix in one side (4.7\%). Another one developed bleeding that only needed pressure and change dressing in the left ear (4.7\%). Adding fascial flap to cover the sutures appears to be beneficial in preventing suture extrusions and granulomas and possibly recurrence by acting as another supporting layer.

Key words: Mustardé otoplasty, Concho-mastoid sutures, Postauricular fascial flap, Suture extrusion, Stitch granulomas and Recurrence.

\section{Introduction}

Prominence is the commonest congenital abnormality of the ear, affecting about $5 \%$ of population with $8 \%$ of those having a positive family history (Firmin et al., 2008, Yugueroes et al., 2001). It is inherited as autosomal dominant with incomplete penetrance (Janis et al., 2005, San Martín et al., 2011). There is no apparent 
sex predilection (Tan and Gault, 1994).

The two most common deformities that account either individually or in combination; are an overdeveloped or deep conchal bowl $(>1.5 \mathrm{~cm})$ and an underdevelopment of the antihelical fold (conchoscaphal angle greater than $90^{\circ}$ ) (Figure 1). Prominence of the antitragus and lobule are other causes that are probably the most resistant to correction. Cranial abnormalities (influencing the base on which the ear rests), and anterolateral displacement of the tail of the helix account for the remaining minority of ear prominence (Cortes and Gosain, 2009)

Despite its benign physiologic consequences, numerous studies attest to psychological distress, emotional trauma, and behavioural problems this deformity can inflict on children (Songu and Adibelli, 2010; Bradbury et al., 1992; CooperHobson and Jaffe, 2009). They found increased happiness and self-confidence in majority of cases with improvement in social integration (97\%, $92 \%$, and $78 \%$ respectively) and decreased bullying by their peers (100\%) (Cooper-Hobson and Jaffe, 2009).

In the last century, at a range of two new methods per year have been described indicating that there is no single widely adopted procedure by most surgeons, including methods that excise, bend, suture, scratch or reposition the auricular cartilage (Janis et al., 2005).

\section{History:}

Dieffenbach (1845) is credited with the first otoplasty for the protruding ear (posttraumatic). Ely described his technique for elective correction

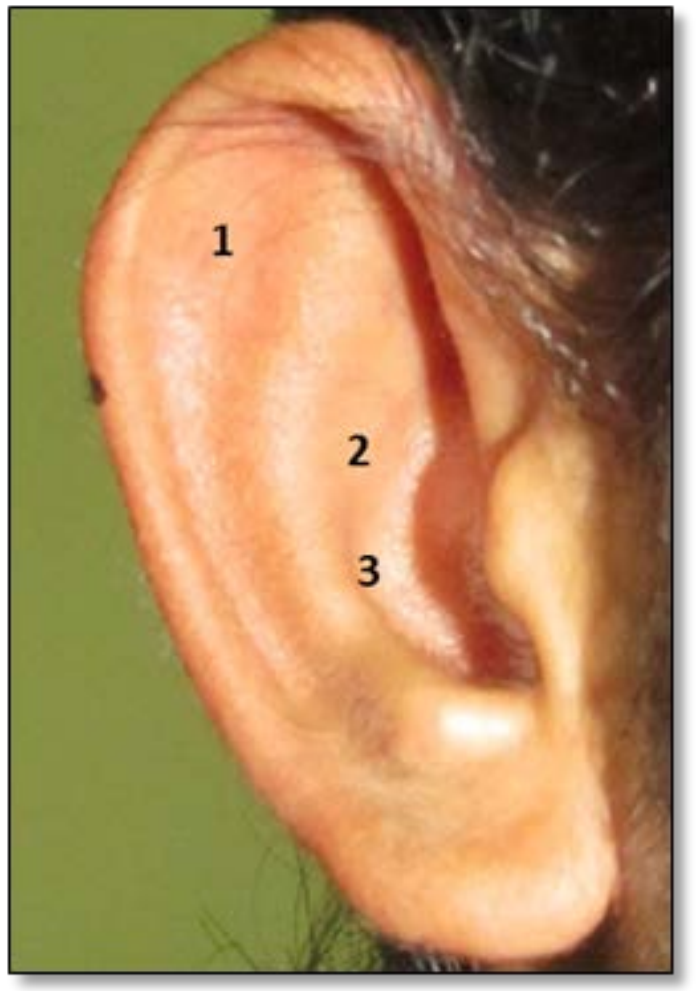

Figure 1: The main deformities contributed to the prominent ears. 1; Loss of antihelical fold. 2; conchoscaphal angle greater than $90^{\circ}$ and 3; conchal excess.

of the prominent ear in 1881 using a postauricular skin excision, conchomastoidal fixation, and conchal strip excision in a two stage procedure performing on each site separately. In 1903, Morestin devised a method of excising the conchal cartilage at the medial wall to break the "spring" of the cartilage; this served to medialise the antihelix and decrease the projection of the concha (Adamson et al., 2010).

Luckett identified the failure of scaphal folding to be the cause of ear prominence and described a combination of cartilage excision with horizontal mattress sutures to create the antihelical fold that is in 1910 (Adamson et al., 2010).

Becker, in 1952, introduced the concept of conical antihelical tubing (Adamson et al, 2010). This technique was later refined by Converse in 1955 and then Converse and Wood-Smith (Converse 
and Wood-Smith, 1963). Mustardé's approach to the creation of antihelical tubing was to use permanent conchoscaphal horizontal mattress sutures (Mustardé, 1963, Mustardé, 1967).

Gibson (Gibson and Davis, 1958) identified the ability of injured cartilage to warp away from the injured surface. This led to the rise of cartilage scoring techniques in like Chongchet (Chongchet, 1963) who used sharp scoring of the lateral scaphal cartilage (with a blade) to form antihelix and (Stenström, 1963).

Chonchomastoidal suturing was popularized by Furnas (Furnas, 1968). The first medical publications on non-surgical correction of congenital auricular deformities in neonates were published in the late 1980s by Japanese plastic surgeons. (Kurozumi and Ono, 1982; Yotsuyanagi et al, 1998).

Gosain approved a novel approach to correct the prominent ear lobule during otoplasty by three point sutures on skin-dermofatty-mastoid periosteum (Gosain et al., 2003).

Horlock, Misra and Gault advanced a fascial flap from postauricular area to cover sutures in an attempt to prevent suture extrusion (Horlock et al., 2001).

After eight years, Shokrollahi and co-workers modified this flap as being raised laterally on the auricular rim (Shokrollahi et al., 2009).

\section{Anatomy of the External Ear:}

\section{The Auricle:}

It possesses many involutions and folds. The most important of these structures are the helix, antihelix, triangular fossa, scapha, concha, lobule and tragus. Other areas of lesser surgical importance - antitragus, intertragic notch, Darwinian's tubercle, root of the helix and tail of the helix - should be recognized since they might contribute to the overall prominent ear deformity (Figure 2) (Janis et al., 2005).

The embryologic second (hyoid) branchial arch is the predominant contributor leading to the formation of helix, scapha, antihelix, concha, antitragus, and lobule, whereas the first (mandibular) arch only contributes to the tragus and helical crus (Cortes and Gosain, 2009).

\section{The Auricular Layers:}

Owing to a layer of subcutaneous tissue as well as connective tissue that separates the skin from underlying cartilage in the posterior auricular surface characteristically make this surface more mobile than its counterside, which is more adherent (Cortes and Gosain, 2009).

Since this connective tissue layer contains its own blood vessels and nerves, and is an extension of the intrinsic auricular muscle layer, it is regarded as a distint layer and skin flaps of the postauricular region can be viewed in terms of being a fasciocutaneous flap. Histological examination of the postauricular layers, revealed well-developed vascular channels in both the fascial and perichondrial layers, Also, there are many small vascular channels immediately below the dermal layer (Park and Roh, 2002).

\section{The Blood Supply of the external ear:}

The arterial supply of the external ear is manily from the superficial temporal artery and posterior auricular artery, both branches of the external 
carotid artery, with some contribution from the occipital artery (Park et al, 1992).

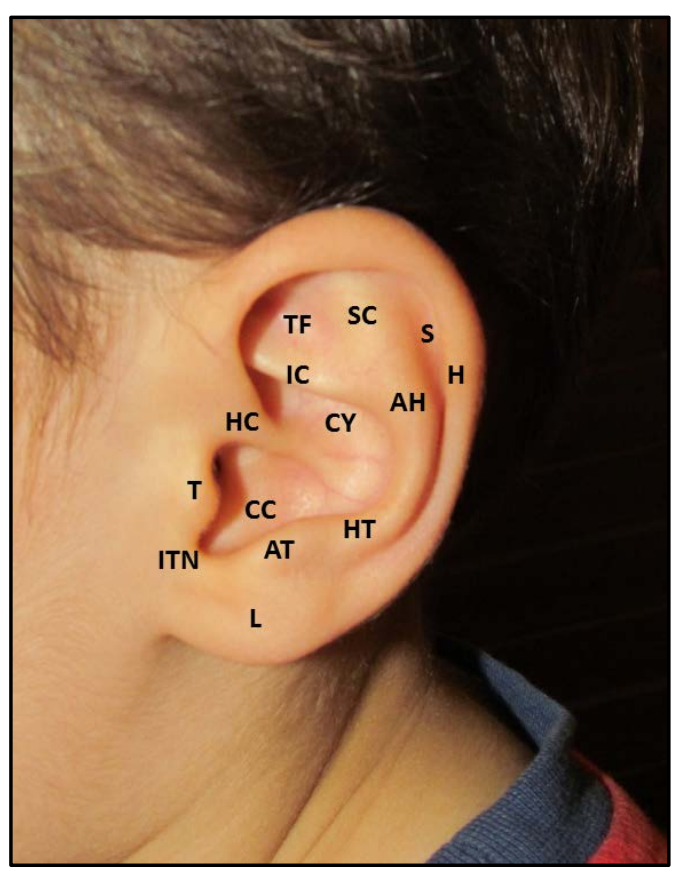

Figure 2: The most important anatomical structures of ear. SC; superior crus, IC; inferior crus, $\mathrm{H}$; helix, $\mathrm{AH}$; antihelix, S; Scapha, TF; triangular fossa, CY; cymba concha, CC; cavum concha, T; tragus, AT; antitragus, ITN; inertragal notch, HT; helical tail, HC; helical crus and L; lobule.

The posterior auricular artery constitute the majority of auricular blood supply. It ascends through the groove between the meatal cartilage and mastoid process and gives off three to five auricular branches. Ultimately it gives off multiple perforating branches to the anteroauricular skin, including perforators to triangular fossa, cymba conchae, helical root, cavum conchae, and earlobe (Figure 3) (Park et al., 1992).

The venous drainage accompanies the arterial supply yet in a much less organization. The lymphatic drainage is to the pre-auricular, postauricular and pre-parotid lymph node groups.

The sensory innervation to the auricle is supplied by contributions from auriculotemporal branch of mandibular nerve (V3), the great auricular and lesser occipital nerves from cervical plexus, the auricular branch of Vagus nerve (Arnold's nerve) and contributions from the facial and glossopharyngeal nerves (Nathan et al., 2002).

\section{Auricular Development:}

The auricle is formed between the $5^{\text {th }}$ and the $9^{\text {th }}$ week of gestation. In the postnatal period, the auricle develops rapidly relatively to other components of the face.

On the basis of the examination of 2300 ears, Adamson and colleagues (Adamson, 1965) stated that $85 \%$ of ear development is completed by the age of three years. Ear width reaches its mature size in boys at 7 years and in girls at 6 years. Ear length matures in boys at 13 years and in girls at 12 (Janz et al., 2009). Matsuo et al. observed that the percentage of protruding ears also increase with time from $0.4 \%$ at birth to $4.4 \%$ at one month to $5.5 \%$ at one year of age (Matsuo et al., 1984).

\section{Timing for otoplasty:}

The optimal timing of surgery for prominent ears continues to be a topic of debate and is poorly understood. Based on auricular development, many feel that otoplasty should not be undertaken until age 4-6 years.

Objective criticisms include aesthetic risk in young patients, and possible delay and/or restriction of growth from early surgical intervention and the potential for increased recurrence of auricular prominence. Gosain, Kumar and Huang have demonstrated that negative growth disturbance does not occur in patients who have undergone otoplasty before 4 years of age (Gosain et al., 2004). 

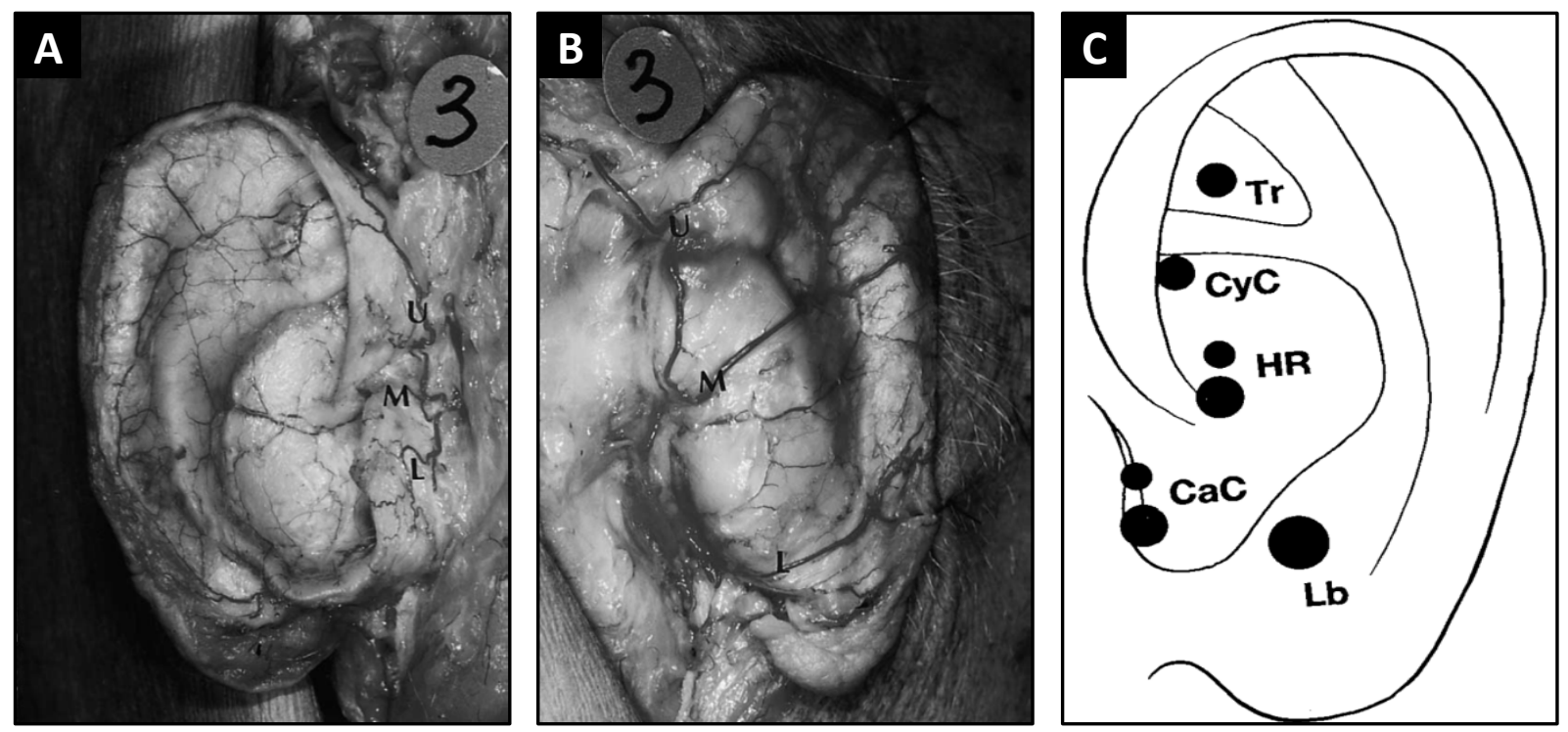

Figure 3: The arterial blood supply of the external ear. A) Superficial Temporal artery branches U; upper, M; middle, and L; lower. B) Posterior auricular artery branches namely U; upper, M; middle and L; lower. C) Posterior auricular artery perforators through the cartilage; \{the larger the dots the larger the perforator is\}. Tr; triangular fossa, CyC; Cymba concha, HR; Helical root, CaC; Cavum concha and Lb; Lobule [From: (Park C, et al, 1992).

Mustardé after ten years of follow-up demonstrated a 1.8 percent versus 30 percent recurrence rates among patients younger and older than 6 years respectively (Mustardé, 1967).

\section{Preoperative Evaluation:}

Achieving success as an otoplasty surgeon requires an appreciation of facial aesthetics, intimate knowledge of ear anatomy, a firm understanding of the rationale for the surgical technique employed, and meticulous attention to technical detail.

To objectively evaluate the abnormal anatomy and the characteristics of aesthetically pleasing ear, certain goals are to be achieved (Table 1).

Preoperative evaluation includes measuring the auriculocephalic distance at the Frankfort horizontal line (a line drawn connecting the infraorbital rim and the superior aspect of the external auditory meatus) on both ears pre and postoperatively. The difference between the two measures (change in medialisation) is used as an objective mean of follow up (Figure 4).

Table 1: McDowell's goals in otoplasty for prominent ears (From: McDowell A J, 1968).

\begin{tabular}{|l|l|}
\hline 1 & $\begin{array}{l}\text { All traces of protrusion in the upper third must } \\
\text { be corrected. }\end{array}$ \\
\hline 2 & $\begin{array}{l}\text { From the front view, the helix of both ears } \\
\text { should be seen beyond the antihelix (at least } \\
\text { down to the mid-way). }\end{array}$ \\
\hline 3 & $\begin{array}{l}\text { The helix should have a smooth and regular } \\
\text { line throughout }\end{array}$ \\
\hline 4 & $\begin{array}{l}\text { The postauricular sulcus should not be } \\
\text { markedly decreased or distorted }\end{array}$ \\
\hline 5 & $\begin{array}{l}\text { The ear should not be placed too close to the } \\
\text { head especially in children (10-12mm at the } \\
\text { top, 16-18mm at the middle portion and 20- } \\
22 m m \text { at the lower third). }\end{array}$ \\
\hline 6 & $\begin{array}{l}\text { Position of the two ears should match fairly } \\
\text { closely to within } 3 \text { mm at any given point. }\end{array}$ \\
\hline
\end{tabular}




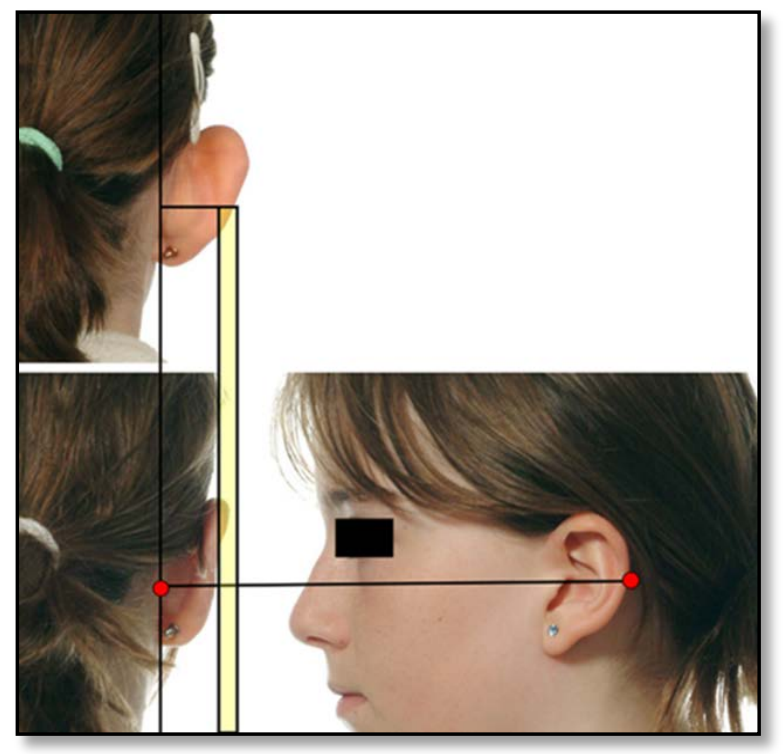

Figure 4: Illustrates how to measure the auriculocephalic distance depending on a fixed bony landmarks (From: Schaverien et al., 2010).

\section{Materials and Methods}

Eleven patients (10 with bilateral and one with unilateral prominent ears) (21 ears), aged 6-32 years with mean age of 15.58 years, two of them were females and nine males (4.5:1 Male/Female ratio), underwent otoplasty technique described by (Shokrollahi, 2009). Patients with Stahl's ear deformity, moderate to severe constricted ear, cryptotia, question mark ear deformity and macrotia were excluded from the study since different approach precluding flap elevation are considered.

The reason for undergoing surgery, the expected result, the family history, drug history, smoking and past medical and surgical history was taken from all of the patients. History of defective wound healing and scar history was also taken. All of our patients were healthy young patients with no history of medical or surgical procedures and no one gave a positive family history of ear prominence.
All the patients were evaluated before surgery for the degree and the cause of prominence, and measurement of the auriculocephalic distance at the Frankfort horizontal line to be compared with post-operative results.

Surgery was performed under general anesthesia in all cases. Both ears were prepped and draped to allow comparing intra-operatively. Dumpbell skin incision is marked on the posterior surface with the outer (lateral) marking line being away from the helical rim by 12-15mm. (Figures 5A and 5B). Although the surgeries were performed under general anesthesia, local anesthetic infiltration of lignocaine $2 \%$ with adrenaline $1: 160000$ to the posterior auricular surface and to the conchal bowl on the anterior surface was also performed.

The technique involves shaving of the dumpbell marking as thin as possible to leave thicker fascial flap (Figure 5B), followed by incising the more medial marking line to elevate the flap supraperichondrally until the sulcus of the helical rim as illustrated by the tip of scissor in (Figure 5C) where the fascia is adherent to the entire helical surface. Hemostasis was secured with bipolar cautery after elevating the flap indicating its robust blood supply (Figure 5D).

All of our patients had loss of antihelical fold underdevelopment and ten of them were also having conchal excess. Adjuvant procedures to the flap are listed in (Table 2).

Sutures that were used include; round half circle Polydioxanone (PDS) (4/0) (6 ears) and Round half circle polypropylene (4/0) (15 ears) for Mustardé holding the cartilage. Flap were fixed in two to three points by round half circle 5/0 (PDS) 
sutures to the mastoid periosteum (Figure 5E) and finally the skin with continuous simple running suturing using PDS 5/0 again.

Table 2: List of adjuvant procedures performed with flap elevation.

\begin{tabular}{|l|c|}
\hline Adjuvant procedure & Ears \\
\hline Mustardé suturing & 21 \\
\hline Furnas concho-mastoid suturing & 20 \\
\hline Conchal cartilage excision & 20 \\
\hline Scoring & 4 \\
\hline Lobule repositioning & 5 \\
\hline
\end{tabular}

We performed dissection of the anterior auricular skin in the area of conchal cartilage resection for a periphery of at least one centimeter in addition to placement of bolster dressing placed on the concha for a period of 2 weeks. An illustration of the steps of the surgery is drawn in (Figure 6). Dressing composed of four layers; paraffin soaked gauze placed in the postauricular groove and pledged into the concavity of concha, fluffy gauze over the ears, cotton balls and crepe bandage. Postoperatively the patients were discharged on the same day if no signs of bleeding and hematoma were observed with full recovery from anesthesia and seen after three days and then after one week, followed by another week visit for suture removal. They were advised to come back if they noticed blood on the dressings, disproportionate pain or dressing took off spontaneously.
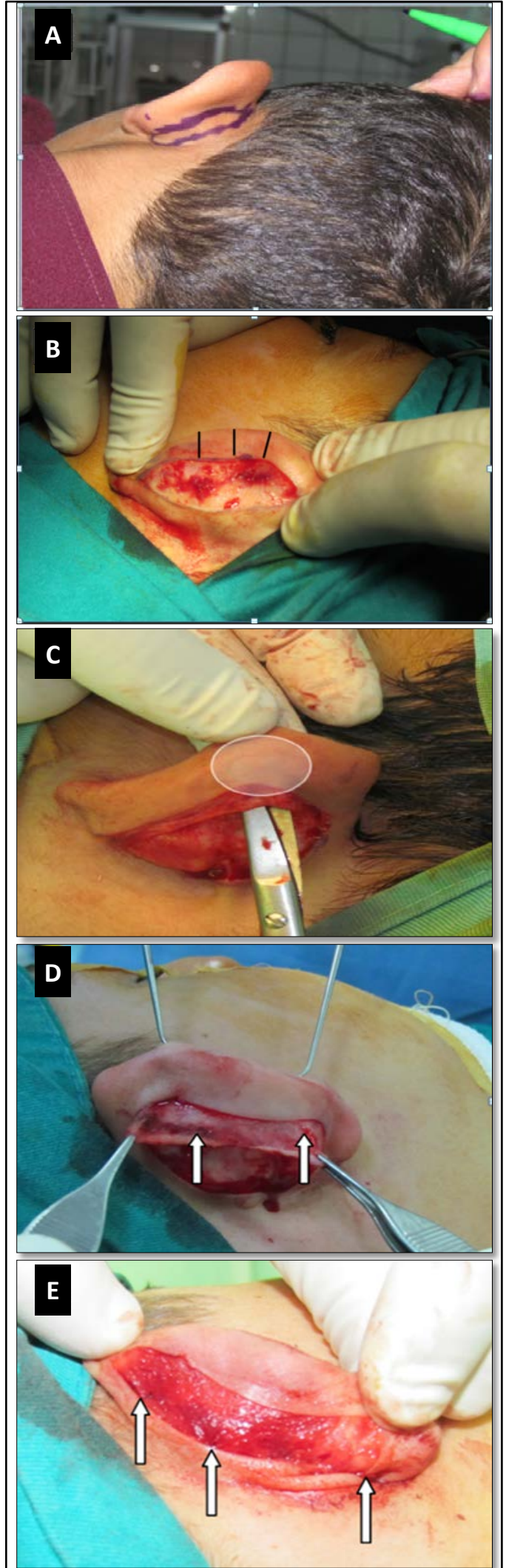

Figure 5: A) The dumpbell epidermis and dermis shaving site on the sulcus which was later modified to lie more laterally. B) Removal with the lateral edge being away from the helical rim by 12-15mm (black dashes). C) The end of dissection as illustrated by the tip of the scissors. D) The flap have been elevated with hemostasis of the bleeding points (white arrows). E) The flap have covered the three suture lines and fixed to the periosteum with buried knots. 
All were advised to wear head bandages for remaining 4 weeks (total of 6 weeks).

\section{Results}

This procedure was performed on eleven patients with prominent ears (ten with bilateral and one with unilateral deformity), their median age was 15.5 years (range 6-32 years). Nine of them were males and two female cases with a male to female ratio of 4.5:1.

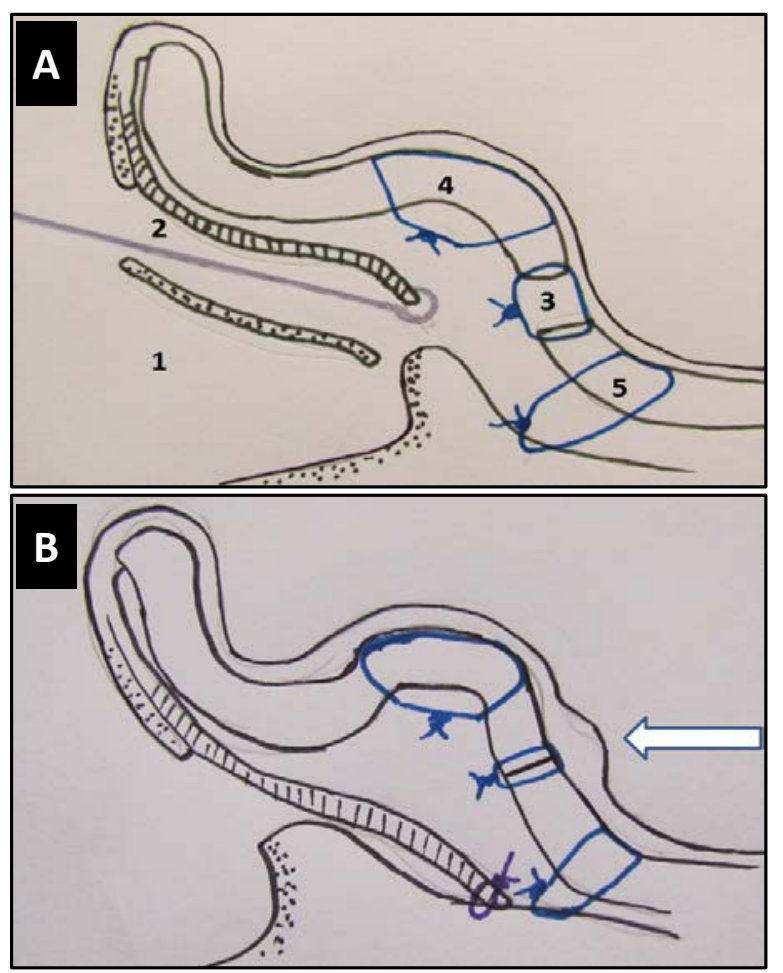

Figure 6: Illustration of the main steps in our procedure. A) 1; Excision of epidermis and part of dermis, 2; Elevation of the posterior auricular flap, its tip hold with a hook, 3; Conchal reduction and suturing, 4; Mustardé sutures and 5; Concho-mastoid sutures is placed pulling the cavum away from the auditory canal precluding its narrowing. B) The flap have covered the three suture lines and fixed to the mastoid periosteum with a purple colored Polydioxanone suture. The white arrow is pointing to the excess skin on the anterior surface after conchal reduction.

The median follow-up period was 242 days (66431 days) nearly eight months. All procedures were performed under general anesthesia. The median auriculo-cephalic distance was $30.2 \mathrm{~mm}$ for the right ear $(27-34 \mathrm{~mm})$ and $28.4 \mathrm{~mm}$ for the left sides (24-33mm) preoperatively and $17.4 \mathrm{~mm}$ $(13-21 \mathrm{~mm}) \quad$ and $\quad 18.2 \mathrm{~mm} \quad(16-21 \mathrm{~mm})$ postoperatively respectively, where the immediate postoperative measurements were kept below 21mm (Figure 7).

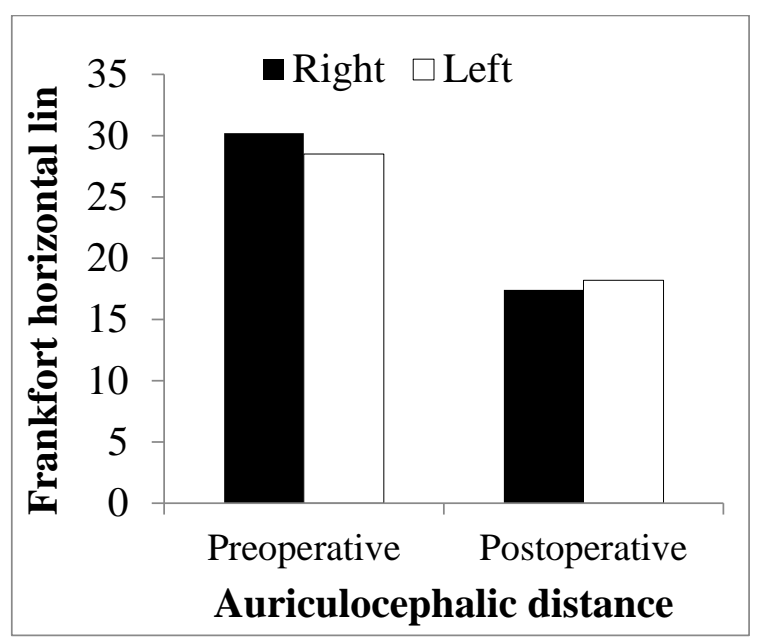

Figure 7: Pre- and postoperative measurement for Ears at Frankfort horizontal line in millimetres in both sides.

Eight Patients were very satisfied with the final shape, position and form of their ears (72.7\%), two patients were satisfied (18.18\%) and only one patient was unsatisfied (9.09\%). Early postoperative complications included postoperative edema in three patients (4 ears, $19 \%)$, and bleeding in one patient (4.7\%) controlled with simple pressure measures. No wound dehiscence, hematoma or infections were observed. Late postoperative complications yielded; hidden helix beyond antihelix in two patients (3 ears, 14.2\%), and partial relapse, prominent ear lobule, residual upper pole prominence in one ear in one of the patient $4.7 \%$ and respectively. Neither major nor minor suture related complications were observed with no keloids or hypertrophic scars. 
Although there are some shortcomings in this comparison, yet the present study favourably yielded fewer complications namely a partial recurrence in one ear (4.7\%). Absence of both major and minor suture related complications for a mean follow-up period of 242 days (nearly 8 months) is largely attributed to the flap coverage.

The pre- and postoperative photos of three cases are shown in (Supplementary Figures S1, S2, and S3).

\section{Discussion}

The ultimate goal for prominent ear correction is the reproduction of natural, symmetrical looking ears with no obvious signs of surgery and minimal complications and recurrences (Schaverien et al., 2010). The patients, or their parents, are concerned about the gross outline, gross contour and gross position of the ears as a whole. (Janz et al., 2009).

High suture extrusion and stitch granulomas as reported by different authors (Yugueroes et al., 2001; Tan, 1986; Thomas and Fatah, 2001) beside high recurrence rates (Tan, 1986) in patients who underwent prominent ear correction with Mustardé sutures made it less preferable. But with the innovation of medially based postauricular fascial flap covering the sutures as an adjunct by Horlock, Misra and Gault that was modified basing laterally by (Shokrollahi et al., 2009) in an attempt to reduce these complications, the cartilage sparing technique rose up again.

None of our patients gave a positive family of the disease despite the fact it some cases run in families but the most commonly it is sporadically. It might be due to small sample size.
Male to female ratio in this study was 4.5:1. This regards as another difference with previous articles as they found no sex predilection, which might be explained due to fact that female patients in our area still use scarfs and with certain hairstyles, they could possibly hide their deformity in order to avoid surgeries and bullying.

The preoperative measures of the auriculocephalic distance were $30.2 \mathrm{~mm}$ for the right side and $28.4 \mathrm{~mm}$ for the left side while the postoperative measures were $17.4 \mathrm{~mm}$ and $18.2 \mathrm{~mm}$ for both ears respectively. The change in medialisation (the difference between the two measures) is greater on the right side because one of our patients had a postoperative value of $13 \mathrm{~mm}$ on the right side decreasing the mean. Furthermore, we were more conservative on the side of lesser distance than on the wider side suspecting that a degree of lateralization might occur with time.

Rigg et al., (2001) in a series of 101 patients found that all of cases of suture granulomas and extrusions were related to Mustardé antihelical tubing. And in order for the flap to have complete coverage on the three suture lines, Mustardé, Furnas and conchal excision, especially on the antihelix we modified the position of the skin marking and shaving to lie more laterally. It would also prevent postauricular sulcus distortion and thereby reducing stuck-on appearance. Lastly the scar resulting from closure will lie in the posterior auricular groove made by tubing of the antihelix.

It is important to reach almost the rim during dissection for providing good exposure for suture placement near the rim. It also decreases the risk of flap entrapment when tying the sutures and 
most importantly it provides uniform pull on the helical rim giving a smooth round antihelix.

It is well known that conchal reduction through posterior approach is associated with redundant anterior conchal skin that may not conform to the remodeled conchal bowl, leaving a wrinkled appearance. This was the rationale for chondrocutaneous resection. But with our cases we tried to solve this problem with anterior skin dissection for about one centimeter periphery of conchal resection plus molding paraffin soaked gauze in to the conchal bowl for two weeks. And a comparison of patients is given in (Figure 8).

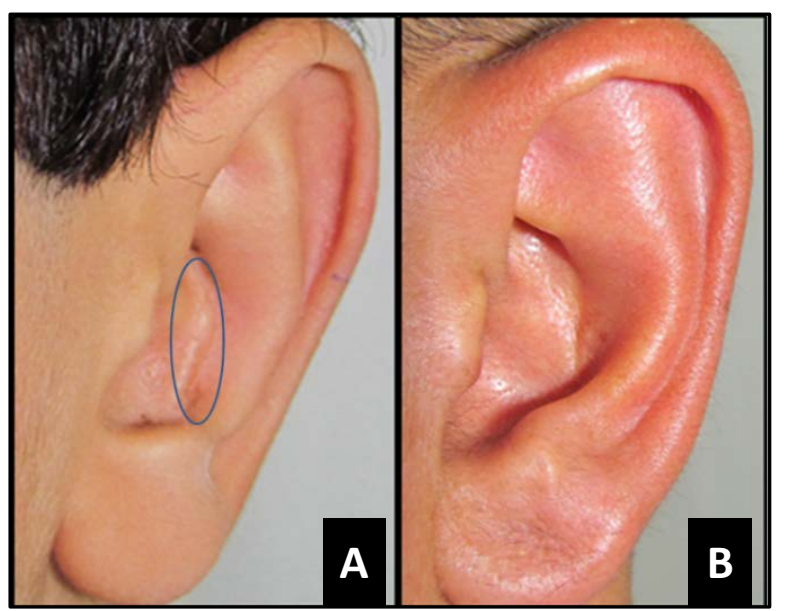

Figure 8: Shows the difference between; A) left ear of a patient ten months after surgery without dissection and paraffin soaked bolsters causing wrinkling (blue circle) and B) left ear of another patient five months after dissection and paraffin soaked bolsters with very minimum wrinkling despite the excision was $10 \mathrm{~mm}$ in width in both patients.

With this technique, patients and their parents were generally satisfied with the results in terms of shape, and symmetry. Seventy-two percent were very satisfied, $18.18 \%$ were satisfied and only one patient (9.09\%) was dissatisfied owing to obvious asymmetry and underwent surgery to deal with residual deformities.
Major suture related complications included signs of chronic inflammation, (redness, itching, pain and discharge) stitch granuloma, sinus formation or extrusion. Minor complications include palpable knots or visible fine threads that are asymptomatic.

Neither major nor minor suture related complications were observed in these patients. No keloid or hypertrophic scar has been seen in these patients. Bleeding occurred in one ear (4.7\%) that was treated with pressure and wound care and stopped without the need for reoperation or hematoma formation. In reviewing other complications in this dissertation like prominent upper and lower poles in one patient and hidden helix in two patients, those complications could occur with any procedure and they might be due improper technique rather than to be caused by the flap.

The following table contains a comparison of our method with some of the published articles and the original papers of (Shokrollahi et al, 2009) in terms of their number of patients, the method and the suture material they used and their final complication rates (Table 3).

Comparing our results with those published data, the absence of suture related complications in flap series is largely attributed to the use of the fascial flap. (Shokrollahi et al., 2009) in another report had only $1.7 \%$ suture extrusion in one ear that is again lower than other articles. In a period of 8 months, none of our patients report neither major nor minor suture related complication. The flap also produces a smooth outline of antihelix by applying a uniform pull of differing degree on each of the ear poles. 
Table 3: A comparison table illustrates the differences in complication rates between our technique and some of the published researches.

\begin{tabular}{|c|c|c|c|c|c|c|c|c|}
\hline 㟃 & 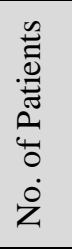 & 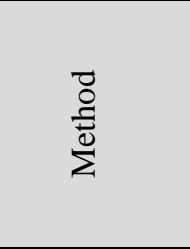 & 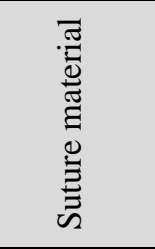 & 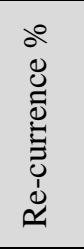 & 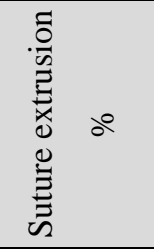 & 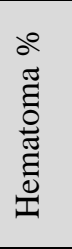 & 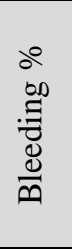 & 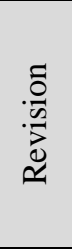 \\
\hline Tan K, 1986 & 45 & Mustardé & white silk & 24.4 & 15 & NS & 33 & $\mathrm{NM}$ \\
\hline $\begin{array}{c}\text { Thomas SS } \\
\text { and Fatah F } \\
2001\end{array}$ & 32 & $\begin{array}{l}\text { Sculpting + } \\
\text { Mustardé }\end{array}$ & prolene & 3.1 & 3.1 & 0 & 0 & 3.1 \\
\hline $\begin{array}{c}\text { Yugueroes P } \\
\text { and Friedland } \\
\text { J A } 2001\end{array}$ & 100 & $\begin{array}{l}\text { Sculpting + } \\
\text { Mustardé }\end{array}$ & nylon & 6 & 19 & 0 & 0 & 6 \\
\hline $\begin{array}{c}\text { Sinha M et al } \\
2012\end{array}$ & 94 & $\begin{array}{c}\text { Mustardé \& } \\
\text { Furnas }\end{array}$ & $\begin{array}{l}\text { Ethibond } \\
\text { prolene }\end{array}$ & 8 & $\begin{array}{c}\text { Occur but } \\
\text { no } \%\end{array}$ & NM & NM & 6.6 \\
\hline $\begin{array}{c}\text { Shokrollahi K } \\
\text { et al } 2009\end{array}$ & 15 & $\begin{array}{c}\text { Mustardé } \\
\text { plus the flap }\end{array}$ & Prolene & 0 & 0 & 0 & 0 & 0 \\
\hline $\begin{array}{c}\text { Schaverien } \\
\text { MV et al } 2010\end{array}$ & 60 & $\begin{array}{c}\text { Mustardé } \\
\text { plus the flap }\end{array}$ & Prolene & 4.5 & 1.7 & 0 & 0 & 5 \\
\hline $\begin{array}{c}\text { Sinha M et al } \\
2012\end{array}$ & 227 & Mustardé & prolene & 3.7 & 2.64 & 0 & NM & 1.32 \\
\hline Present Study & 11 & $\begin{array}{c}\text { Mustardé } \\
\text { plus the flap }\end{array}$ & prolene & 4.7 & 0 & 0 & 4.7 & 0 \\
\hline
\end{tabular}

Accurate description of the problem is to calculate complications in each ear separately as it was recommended by (Limandjaja, et al., 2009) who reviewed more than 205 articles.

Compiling to this recommendation we calculated complications in our series rated on number of ears affected by the problem rather than the number of patients. A $4.7 \%$ recurrence in one ear that was partial in one of the first cases in whom Polydioxanone (PDS) suture have been used could be explained to be due the inherent properties of late absorption of this suture material.
This was the reason why we used polypropylene for both Mustardé and Furnas concho-mastoid suturing in the rest of patients. While still we used polydiaxonone for the flap fixation as the time needed for complete absorption of this material is nearly (6) months a time fair for the fibrosis and adhesion to occur holding the flap in its position.

\section{Conclusions}

The post-auricular fascial flap as described by (Shokrollahi et al., 2009) yields excellent patients and parent satisfaction with natural harmonious look and minimal complication especially those 
related to sutures demonstrating its efficacy in preventing these complications. Although a (4.7\%) partial recurrence that appeared may be attributed the use of Polydioxanone suture or suture cheese wiring through the cartilage, yet when comparing with other studies it favourably much less without complete recurrence that appeared in some well-known published references. Dissecting the anterior skin for a periphery of one centimetre through the conchal excision wound beside placement of bolsters in the concha reduces the risk of anterior skin wrinkling associated with conchal excision through posterior approach.

\section{References}

Firmin F, Sanger C, and O'Toole G (2008). Ear reconstruction following severe complications of otoplasty. J Plast Reconstr Aesthe Surg. 61: S13-20.

Yugueroes P. and Friedland J A (2001). Otoplasty; the Experience of 100 Consecutive Patients. Plast Reconstr Surg. 108(4): 1045-51.

Janis J E, Rohrich R J, Gutowski K A (2005). Otoplasty. Plast Reconstr Surg. 115(4):60e-72e.

San Martín RE, et al. Otoplasty (2011). Results After Anterior Versus Posterior Approach. Acta Otorrinolaringol Esp. 62(3):188-93.

Tan S T and Gault D T (1994). When do ears become prominent? Br J of Plast Surg. 47, 573-4.

Cortes W and Gosain AK (2009). Prominent ears, in: Guyuron B, editor. Plastic surgery; indications and practice. 1st edition. Saunders Elsevier. Vol.1 p.701-716.

Songu M and Adibelli H (2010). Otoplasty in children younger than 5 years of age. International Journal of Pediatric Otorhinolaryngology. (74) p.292-296.

Bradbury E, Hewison J, Timmons M (1992). Psychological and social outcome of prominent ear correction in children. Br J Plast Surg. 45:97-100.

Cooper-Hobson G and Jaffe W (2009). The benefits of otoplasty for children: Further evidence to satisfy the modern NHS. J Plast Reconstr Aesthe Surg. 62, 190-194.

Adamson PC, Doud Galli S K and Chen T (2010). Otoplasty, in: Flint PW, et al. (eds) Otolaryngology: head and neck surgery. 5th edition. Philadelphia: Mosby (Elsevier). 1134I.

Converse J M and Wood-Smith D (1963). Technical details in the surgical correction of the lop ear deformity. Plast. Reconstr. Surg. 31: 118-128.

Mustardé JC (1963). The correction of prominent ears using simple mattress sutures. Br J Plast Surg 16:170-8.

Mustardé J C (1967). The treatment of prominent ears by buried mattress sutures; a ten year survey. Plast. Reconstr. Surg.37:382-6.

Gibson, T., and Davis, W. B (1958). The distortion of autogenous cartilage graft: Its cause and prevention. Br. J.Plast. Surg.10: 257.

Chongchet V (1963). A method of antihelix reconstruction. Br J Plas Surg.16:268-72

Stenstrom S (1963). A natural technique for correction of congenitally prominent ears. Plast. Reconstr. Surg. 32:509-18.

Furnas, D. W (1968). Correction of prominent ears by conchamastoid sutures. Plast. Reconstr. Surg.42: 189.

Kurozumi N, Ono S, Ishida H (1982). Nonsurgical correction of a congenital lop ear deformity by splinting with Reston Foam. Br J Plast Surg.35:1812.

Yotsuyanagi T, Yokoi K, Urushidate S, et al 1998). Nonsurgical correction of congenital auricular deformities in children older than early Neonates. Plast Reconstr Surg (101:907-14.

Gosain AK, Recinos RF (2003). A novel approach to correction of the prominent lobule during otoplasty. Plast Reconstr Surg.112 (2):575-83.

Horlock N, Misra A, Gault DT (2001). The postauricular fascial flap as an adjunct to Mustarde' and Furnas type otoplasty. Plast Reconstr Surg. 108: 1487-90.

Shokrollahi K, Cooper MA, Hiew LY (2009). A new strategy for otoplasty. J Plast Reconstr Aesthet Surg. 62(6):774-81.

Park C and Roh TS (2002). Anatomy and embryology of the external ear and their clinical correlation. Clin Plastic Surg . 29: 155- 174.

Park C, Lineaweaver WC, Rumly TO, et al (1992). Arterial supply of the anterior ear. Plast Reconstr Surg. 90:38-44.

Nathan N et al. Otoplasty (2002). In Facial plastic and reconstructive surgery. Ira D Papel (Editors) 2nd Ed. Thieme Medical Publishers. p 309.

Adamson J E, Horton C E, and Crawford H H (1965). The growth pattern of the external ear. Plast. Reconstr. Surg. 36: 466. 
Janz B, Cole P, Hollier L and Stal S (2009). Treatment of Prominent and Constricted Ear Anomalies. Plast Reconstr Surg.124; p 27e-37e.

Matsuo K, Hirose T, Tomono T, et al (1984). Nonsurgical correction of auricular deformities in the early neonate: a preliminary report. Plast Reconstr Surg. 73:38-50.

Gosain AK, Kumar A, Huang G (2004). Prominent ears in children younger than 4 years of age: what is the appropriate timing for otoplasty? Plast Reconstr Surg. I 14 (5):1042-1054.

McDowell, A. J (1968). Goals in otoplasty for protruding ears. Plast. Reconstr. Surg. 41: 17-27.

Schaverien MV, Al-Busaidi S, Stewart KJ (2010). Long-term results of posterior suturing with postauricular fascial flap otoplasty. J Plast Reconstr Aesthet Surg. 63(9): 1447-51.

Tan K (1986). Long term survey of prominent ear surgery: a comparison of two methods. Br J Plast Surg. 39:270-3.

Rigg BM (1979). Suture materials in otoplasty. Plast Reconstr Surg. 63(3): 409-410.

Thomas SS, Fatah F (2001). Closed anterior scoring for prominent ear correction revisited. Br J Plast Surg. 54: 581-7.

Mandal A, Bahia H, Ahmad T, Stewart KJ (2006). Comparison of cartilage scoring and cartilage sparing otoplasty; A study of 203 cases. J Plast Reconstr Aesthet Surg. 59:1170-6.

Sinha, M and Richard B (2012). Postauricular Fascial Flap \& Suture Otoplasty; A Prospective Outcome Study of 227 Patients. J. Plast, Reconstr. Aesth. Surg. 65, 367-371.

Limandjaja G.C, Breugem C.C, Mink van der Molen, and Kon M (2009). Complications of otoplasty: a literature review. . J Plast Reconstr Aesthet Surg. 62, 19-27. 


\section{Supplementary Figures:}
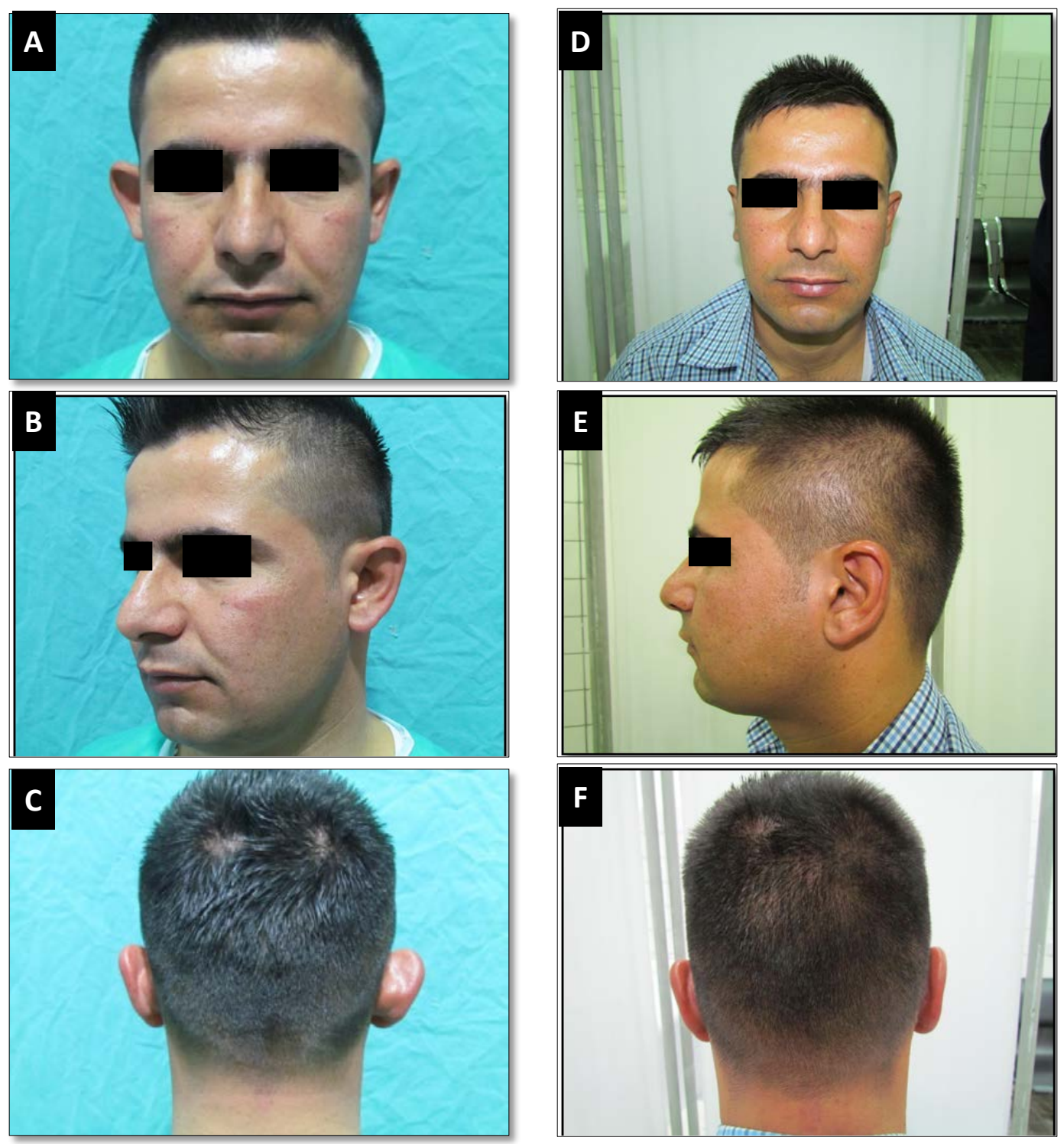

Figure S1: Shows case number (1) who is 28 years old man with bilateral asymmetrical prominent ears with preoperative photos on the left side (A-C) and six months post-operative views on the right side (D-F). 

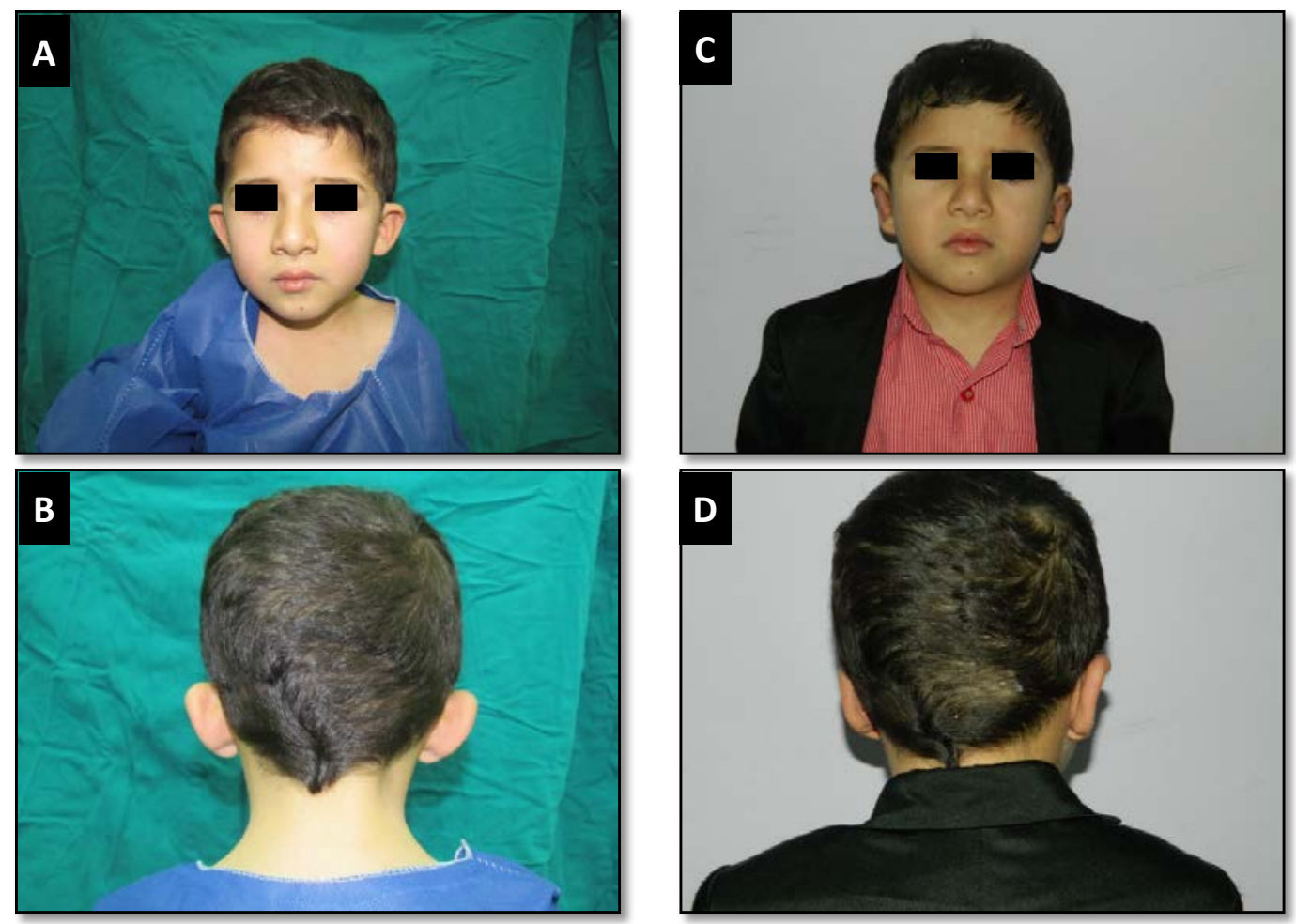

Figure S2: Shows case number (2) who is a 6 years old boy with mild degree of constricted ear deformity and prominence. Preoperative photos on the left side (A \& B) and postoperative views on the right (C \& D) eight months later.
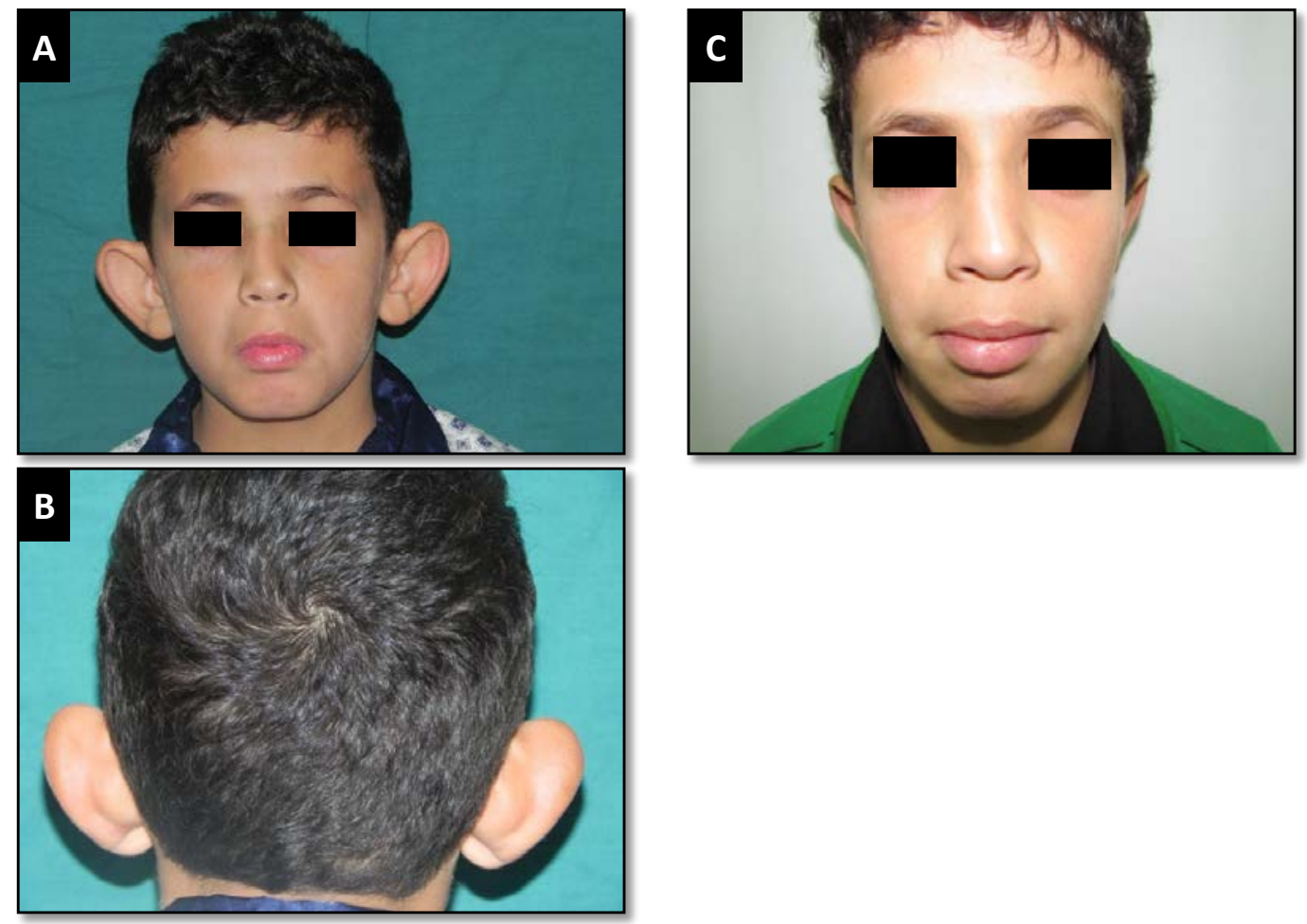

Figure S3: Shows case number (3) who is a 10 years old boy with bilateral prominent ears both anterior and posterior views preoperatively on the left side (A \& B) and postoperatively on the right side (C) eight months after surgery.

Note: permission was taken from these patients and their families for taking and publishing their photos in the contest of the dissertation and its presentations only. 